\title{
Expanding access and method choice: Evidence of client self- administration of injectables and private sector provision of family planning services in three West African countries
}

Evidence Project

Follow this and additional works at: https://knowledgecommons.popcouncil.org/departments_sbsr-rh How does access to this work benefit you? Let us know!

\section{Recommended Citation}

Evidence Project. 2020. "Expanding access and method choice: Evidence of client self-administration of injectables and private sector provision of family planning services in three West African countries," Learnings from the Evidence Project. Washington, DC: Population Council, The Evidence Project. 

Ouagadougou Partnership, and through targeted national strategies. Ghana, Nigeria and Senegal, among other countries, have been exploring new strategies to expand access to voluntary FP service delivery. Context-specific evidence was needed for two promising strategies-1) task sharing of FP services to private sector drug shops and pharmacies and 2) introducing self-injection of subcutaneous depot medroxyprogesterone acetate (DMPA-SC).

The Evidence Project collaborated with stakeholders in Ghana, Nigeria, and Senegal to use implementation science (IS) to expand the evidence base on these promising approaches. In this brief, we describe key study results from the three countries and how results have been used to increase access to voluntary family planning and expand method choice.

\section{The Evidence Project explored task sharing with drug shops and pharmacies as well as self- administration of injectables to improve equitable access to voluntary family planning}

Previous studies have shown that task sharing contraceptive services to private sector drug outlets and including self-administered methods in the method mix can improve access to voluntary FP services, especially for underserved and marginalized populations [4-9]. Task sharing is defined as "an expansion of the levels of health providers who can appropriately deliver health services" [5]. By sharing certain tasks across provider types, some benefits of task sharing include increasing access to and availability of contraception and giving higher skilled clinicians more time to use their specialized skills or focus on complex tasks [5]. Self-administration of DMPA-SC has the potential to improve access, choice, continuation, and autonomy in countries that allow women to self-administer DMPA-SC in or outside of a health facility $[6,7]$.

From 2013 to 2019, the Evidence Project collaborated with ministries of health (MOHs) in Ghana, Nigeria, and Senegal to explore ways to improve access to voluntary contraceptive services through task sharing and self-administered methods. Figure 1 provides an overview of the studies conducted in Ghana [10], Nigeria [11,12], Senegal [13-15]. Full descriptions of the study design, results, and IS process can be found on the Evidence Project website.

\section{OUR IMPLEMENTATION SCIENCE APPROACH}

The Evidence Project used implementation science (IS)-the strategic generation, translation, and use of evidence-to strengthen, scale-up, and sustain voluntary family planning (FP) services.

Our IS approach was driven by collaboration with partners to: (1) define research priorities; (2) implement research activities; and (3) use evidence for decision-making.

This brief is part of a series of briefs synthesizing evidence and lessons learned through the project. Other briefs include:

- Expanding access to voluntary FP through new approaches to workplace interventions

- Innovating and validating measures of complex concepts

These briefs and all other Evidence Project publications can be found at: http://evidenceproject.popcouncil.org/.

\section{DMPA-SC, including self-injection, and drug shop provision of injectable contraceptives were acceptable and reached new contraceptive users as well as young
people}

In Ghana, 568 women who sought FP services from a public health facility and voluntarily chose DMPA-SC (after receiving FP counseling) were interviewed following their initial visit and up to two additional times, coinciding with

\section{DMPA-SC AND TASK SHARING REACHED NEW USERS}

- $41 \%$ of DMPA-SC clients in Ghana were first-time FP users

- $42 \%$ of injectable clients in Nigeria began a new episode of use at their visit to a PPMV

Sayana $\AA$ Press (a registered trademark of Pfizer Inc.) was the brand of DMPA-SC used in this study. 


\section{FIGURE 1. STUDY IMPLEMENTATION SITES *}

\section{SENEGAL FP SNAPSHOT}

18\% modern contraceptive prevalence rate (mCPR)

55\% FP demand satisfied by modern methods

Injectables (6\%); implants (6\%); and pills (3\%)-most commonly used modern methods

\section{STUDY OVERVIEW}

Phase 1: Exploratory study

- Explored barriers to and opportunities for the provision of voluntary FP by private pharmacies

- Conducted literature and legal reviews, secondary data analysis, and key informant interviews

Phase 2: Pilot study

- Trained private pharmacy staff and assessed the feasibility of these staff to offer counseling, and oral and injectable contraceptives

- Conducted interviews with private pharmacies and used mystery clients to assess FP counseling skills of staff from participating pharmacies

\section{GHANA FP SNAPSHOT}

$18 \% \mathrm{mCPR}$

41\% FP demand satisfied by modern methods

Injectables (6\%), implants (4\%), and pills (4\%)-most commonly used modern methods

\section{STUDY OVERVIEW}

- Assessed the feasibility and acceptability of DMPA-SC self- and/or provider-administered injection through public sector channels

- Conducted interviews with 1) providers pre- and post-training and 2) clients over 6-month period after initiating DMPA-SC use

\section{NIGERIA FP SNAPSHOT}

\section{$11 \% \mathrm{mCPR}$}

$36 \%$ FP demand satisfied by modern methods

Implants (3\%), male condoms (3\%), and injectables (2\%)-most commonly used modern methods

\section{STUDY OVERVIEW}

- Assessed the feasibility and acceptability of providing injectables by trained proprietary medicine vendors (PPMVs)

- Conducted multiple interviews with 1) PPMVs over 9-month period and 2) clients of PPMVs over 9-month period

*Country FP snapshots include data for all women 15-49 years old from the latest Demographic and Health Surveys for Ghana (2014), Nigeria (2018), and Senegal (2018) [16].

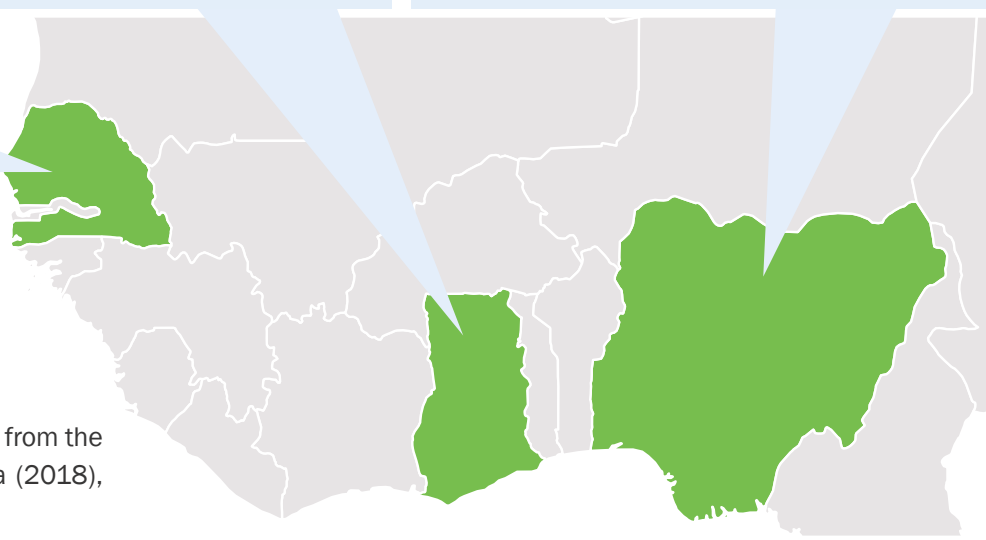

their contraceptive follow-up injections. At each injection, women were given the option to self-inject DMPA-SC or have the provider administer it [10]. Of the 378 women who continued to use DMPA-SC through their third injection, 72 percent chose to self-inject (either at home or on-site) while 28 percent chose provider administration. As the Ghana Health Service scales up DMPA-SC nationally, it will be important for the scale-up program to provide women with options for administration modes.

In Nigeria, 561 clients were interviewed within five days of receiving injectable contraceptives from private sector Patent and Proprietary Medicine Vendors (PPMVs). Forty-two percent of clients reported starting a new episode of injectable contraceptive use and 61 percent of all clients interviewed had not previously received injectable contraceptives from a PPMV. Common reasons for choosing PPMVs included convenient location, anonymous care, personally knowing the PPMV, and no waiting time [11]. Clients also reported high satisfaction with the services received by PPMVs and nearly all (99 percent) said they would go back to the PPMV for their next injection. These results confirm that PPMVs represent an important and feasible outlet for increasing access to voluntary FP in $\mathrm{Ni}$ geria.

\section{YOUNG PEOPLE FOUND NEW APPROACHES AND SOURCES OF FP ACCEPTABLE}

- In Ghana, 33\% of DMPA-SC clients were under 24 $(n=185)$, and $98 \%$ of them intended to continue using DMPA-SC after their first injection. Among young women who chose self-injection at their initial visit and were still using DMPA-SC six months later $(n=54), 94 \%$ continued to self-inject.

- In Nigeria, $12 \%$ of PPMV clients were under 24 years of age $(n=69)$, and after their first injection, all said they would return to the same PPMV to continue their method. 
Before the pilot study in Senegal was initiated, the Evidence Project explored opportunities for and barriers to private pharmacy provision of FP services. Through a literature review, the Evidence Project found that 43-46 percent of existing private pharmacy clients would be interested in directly obtaining oral or injectable contraceptives from private pharmacies [14]. Secondary data analysis of data collected by L'Agence pour le Développement du Marketing Social (ADEMAS) also found that private pharmacies distribute a larger percentage of short-acting contraceptive methods compared to public health facilities [15]. The legal review found that Article 569 from the April 1954 law states that "the operation of a pharmacy is incompatible with the practice of another profession, particularly that of a medical practitioner, a veterinarian, a midwife, or a dentist." This means that while private pharmacies can sell condoms and emergency contraceptives over the counter and oral, injectable implant, and IUD contraceptives ${ }^{\mathrm{ii}}$ with a prescription, they are not permitted to prescribe or administer contraceptive methods [14].

iMethods such as the injectable, implant, and IUD may be purchased with a prescription but are administered by a qualified heath professional.

\section{Women received high quality services}

Quality of care in FP includes the interpersonal relations and exchange of information between a provider and a client. It can be measured in terms of quality of care offered by providers through observations of counseling and mystery clients, and quality of care received as reported by clients (typically through client exit interviews). In Ghana and Nigeria, client exit interviews were used to capture quality of care received by clients from public sector providers and PPMVs. In Senegal, mystery clients were used to observe the quality of care offered by private pharmacies. Figure 2 shows the proportion of FP clients in Ghana and Nigeria who reported that they received information on seven quality of care questions during their initial visit.i.i In Ghana, 62 percent of clients reported receiving information on all seven components of quality of care. For individual ques-

iiiUnder the Evidence Project, Jain et al. [17] validated 22- and 10-item measures to assess quality of care received by clients during FP visits with providers or frontline health workers. The measures cover four domains of quality of care: respectful care, information exchange about method selection, effective use of the selected method, and continuity of contraceptive use and care. The study in Nigeria took place before these measures were validated and thus the measures are not included in this brief but are available here.

FIGURE 2. CLIENTS' REPORTS OF QUALITY OF CARE RECEIVED IN GHANA AND NIGERIA

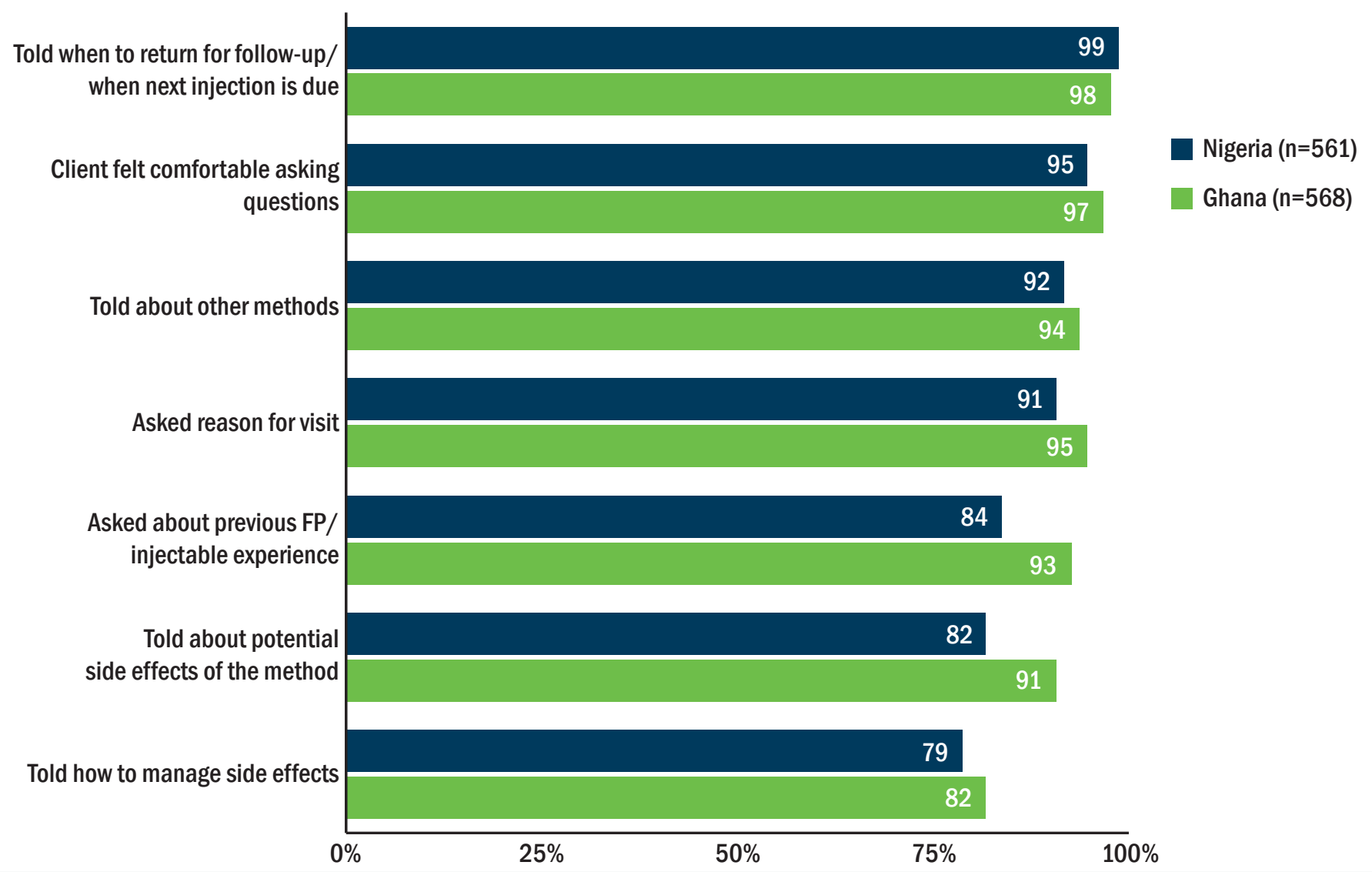


tions, receipt of information ranged from 99 percent of women who reported that they were told when their next injection was due to 79 percent of women who reported that they were told how to manage side effects. These data suggest that clients received high quality of care from the public sector providers participating in the Ghana study.

In Nigeria, 66 percent of women reported receiving all seven components of quality of care. Almost all women $(98 \%)$ reported that they were told when to return for their next injection. While 91 percent reported that they were told about the potential side effects of their injectable contraceptive method, fewer $(82 \%)$ reported being told how to manage those side effects. These results suggest that clients enrolled in this study received high quality of care from PPMVs trained in the study in Nigeria.

In Senegal, 94 percent of mystery clients observed that the pharmacy staff asked them about their past experience with FP, 82 percent were asked if they had a preferred method in mind, and 92 percent discussed other FP methods with pharmacy staff (data not shown). However, some aspects of quality of care were observed less frequently such as discussing side effects (33\%), warning signs $(28 \%)$, and how to manage the side effects of the method $(24 \%)$ (data not shown).

\section{Job aids and client tools provided ongoing, evidence-based support to providers and clients to help them apply new skills}

In all three countries, trained providers were equipped with relevant job aids and received subsequent supportive supervision and monitoring visits. The results from all three country studies suggest that job aids can support providers effectively who are new to offering a service and enable clients to effectively self-administer their contraceptive method if they choose.

In Ghana, the Evidence Project used job aids and client tools for home and self-injection that were developed by PATH. Providers were given a checklist to record the steps clients took when practicing DMPA-SC self-injection on dummy models. The majority of providers reported that they had memorized the steps of the checklist and therefore did not systematically refer to it when observing clients practicing self-injection of DMPA-SC. For clients who selected home self-injection, women were given self-injection

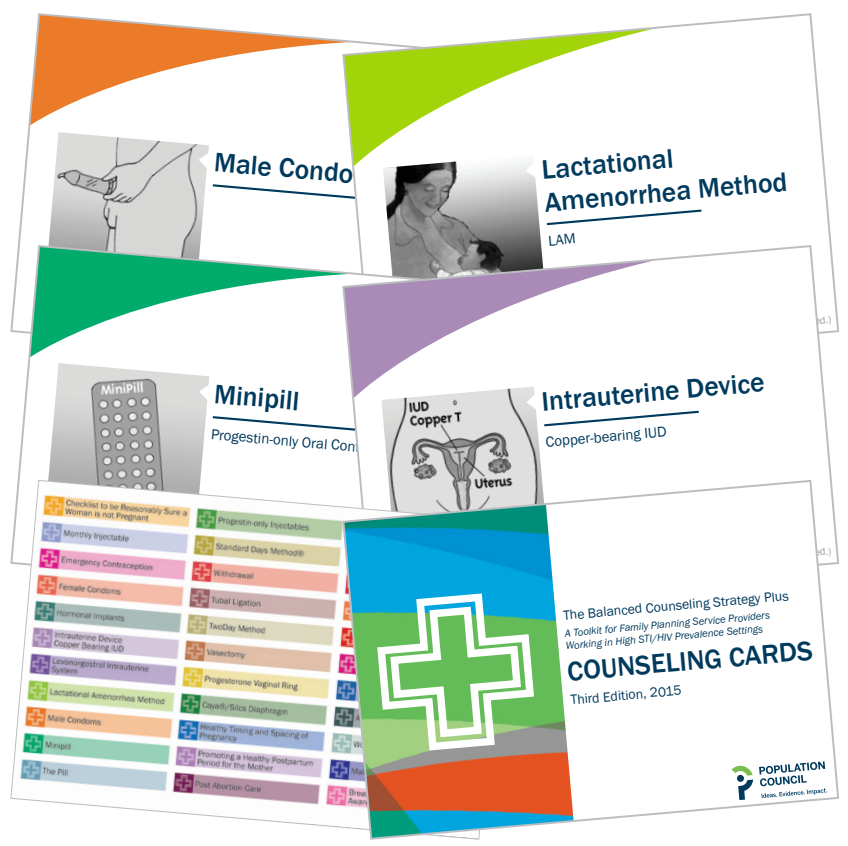

instruction sheets and calendars to remind them of their next DMPA-SC injection. Nearly all clients (95\%) reported using the calendar and most who used it (90\%) found it very useful.

In Nigeria, job aids supported PPMVs in remembering important, detailed information. The majority of PPMVs (86\%) reported using the World Health Organization's Medical Eligibility Criteria Wheel, Population Council's Balanced Counseling Strategy Plus cards, and/or FHI 360 DMPA screening checklist. PPMVs' reported use of job aids was associated with higher levels of injectable contraceptive knowledge nine months after the training [18].

In the Senegal pilot study, mystery clients observed that in nearly three-fourths $(73 \%)$ of their visits, the private pharmacy staff used a job aid while providing FP counseling.

\section{Close collaboration with in-country partners and stakeholders was crucial to develop contextualized approaches and foster research utilization}

In all three countries, the Evidence Project worked closely with key partners and stakeholders, including ministries of health, professional associations, donors and development partners, regulatory agencies, nongovernmental organizations, and private-sector institutions. These close and collaborative relationships informed study design and 


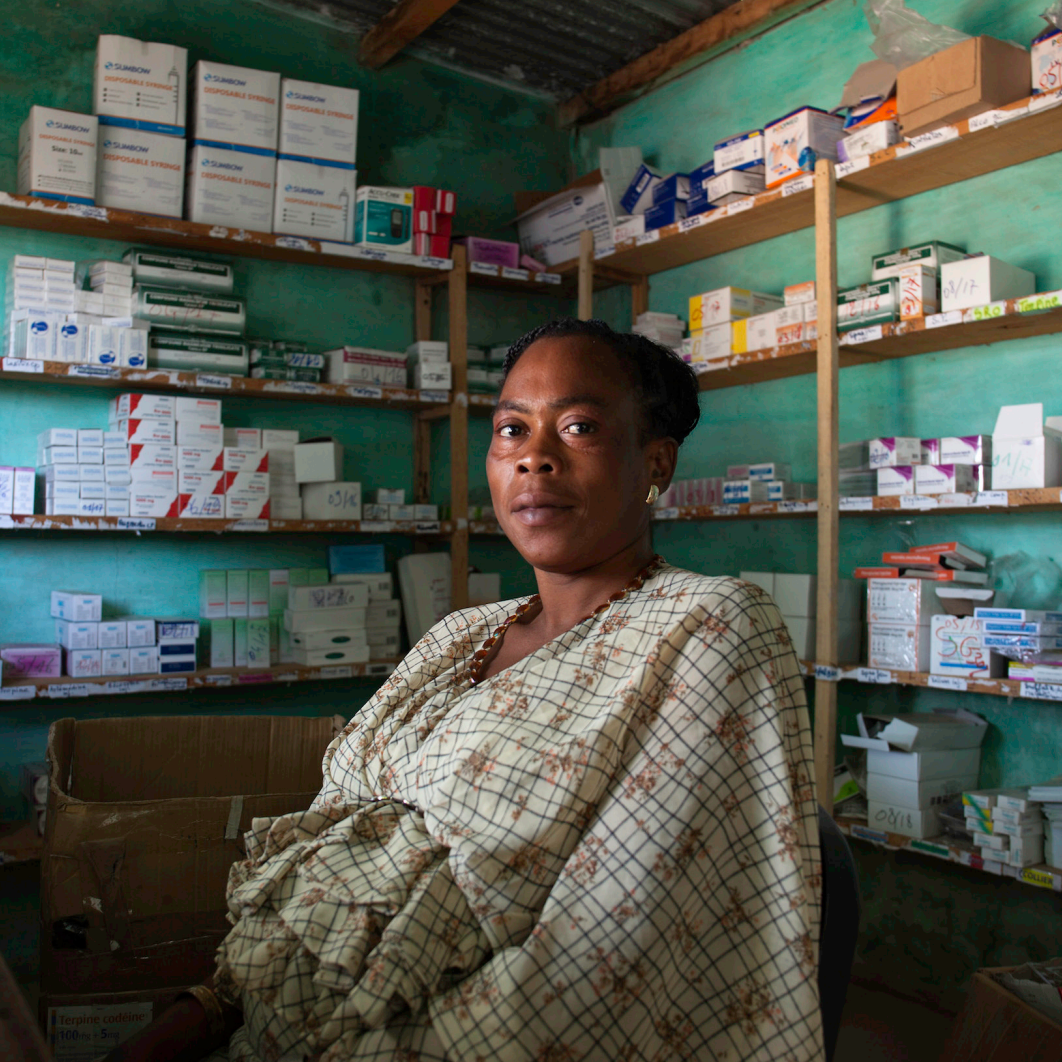

implementation as well as adaptation of global materials ${ }^{\text {iv }}$ and intervention approaches to each country's context. In addition, ongoing stakeholder engagement fostered research utilization and offered opportunities for sustainability and scale up.

In Ghana, study implementation was overseen by the Ghana Health Service (GHS) and guided by a national technical advisory group (TAG). This TAG, led by GHS, was instrumental in informing the study design; adapting intervention approaches and training materials; and conducting monitoring visits to study sites. For instance, based on the TAG's input, concerns about waste management and safe disposal practices were incorporated into the study design and data collection.

Study findings were used subsequently by the GHS to inform national scale-up plans for DMPA-SC and self-injection. Research results, for instance, demonstrated the feasibility of providing clients with a puncture-proof container to store used DMPA-SC devices and instructing them to return the container to the facility for final disposal. This evidence-informed safe disposal practice was incorporated into the national scale-up plans for home self-injection.

In April 2019, Ghana began expanding access to DMPA-SC through service delivery channels in both the

ivaterials consulted included the World Health Organization's Medical Eligibility Criteria [19], PATH's DMPA-SC training curriculum [20, 21], FHI 360's screening checklists for oral and injectable contraceptives $[22,23]$, and the Population Council's Balanced Counseling Strategy Plus [24]. public and private sectors with support from several partners. The GHS used several approaches employed during the study for scaling up DMPA-SC, including home self-injection. The GHS replicated and extended the cascade training approach used in the study to accelerate national scale-up. The same master trainers that were trained for the self-injection pilot study went on to then train regional resource persons in all 16 administrative regions in the country using the same job aids, checklists, and client tools that were adapted for this study. In addition, the study contributed evidence to inform national procurement plans and routine monitoring of DMPA-SC services in Ghana. Daily logbooks, monthly registers, and health information systems were recently revised to enable monitoring of DMPA-SC counseling, administration (specifying provider- or self-administered), and commodity tracking.

\section{EXPANDED ACCESS TO AND OPTIONS FOR DMPA-SC ADMINISTRATION IN GHANA}

Evidence generated on the feasibility and acceptability of self-injection in Ghana has informed the government's national DMPA-SC scale-up plans, including approaches to waste management and safe disposal practices.

In Nigeria, the Evidence Project worked in partnership with the Federal Ministry of Health (FMOH), state ministries of health from across the country's geopolitical zones, the National Association of Patent and Proprietary Medicines, and several other nongovernmental partners in a multi-phased IS approach. This group of partners informed the study design and development of FP training materials adapted for PPMVs, and participated in study monitoring visits. At the design phase, for instance, the FMOH co-hosted a stakeholder meeting to garner support for expanding the study design from only assessing PPMVs' ability to counsel and refer clients for injectable contraceptives to also assess PPMVs' ability to administer injectables. Furthermore, a collaborative group of government and nongovernment partners reviewed initial results and learning from two states, Oyo and Nasarawa, to refine the training curriculum and implementation and data collection plans for four additional states: Bauchi, Cross River, Ebonyi, and Cross River.

Evidence from across multiple Nigerian states on the feasibility and acceptability of PPMV provision of injectables 


\section{GREATER METHOD CHOICE AVAILABLE THROUGH PPMVS IN NIGERIA}

Evidence on the feasibility and acceptability of PPMVs providing injectables, in addition to other short-acting contraceptive methods, has informed the country's DMPA-SC scale-up plans. The government, in collaboration with the Population Council and other partners, is currently piloting a tiered accreditation system for PPMVs and community pharmacists to provide more methods, including implants.

was used to expand method choice for women in Nigeria. The FMOH and other partners used study results to include PPMVs in the national DMPA-SC scale up plans. Also, building on the Evidence Project's work, two additional states are now piloting PPMV provision of injectables under another project, supported by the Clinton Health Access Initative. In addition, the government continues to explore formalizing the role of PPMVs in providing a range of voluntary FP methods, including injectables and potentially implants, through a tiered accreditation system under the IntegratE Project. Partners in Nigeria, including the Population Council and others, are currently collaborating to pilot this new tiered accreditation system to continue to expand method choice through PPMVs and community pharmacists.

In Senegal, the Evidence Project collaborated with champions within the $\mathrm{MOH}$, national research organizations, and professional associations to conduct an exploratory study which led to the $\mathrm{MOH}$ requesting a follow-up pilot study. During the pilot, the Evidence Project continued to work with representatives and trainers from the Directorate of Maternal and Child Health alongside representatives from the Pharmacists Order of Senegal to adapt the Nigeria PPMV training curriculum, in addition to other global and local learning materials [19-25], for use with private pharmacies. The training, for instance, was shortened based on guidance from the Pharmacists Order to ensure participation from busy private pharmacists. Additional modifications were also required since the legal framework in Senegal restricted services participating pharmacies could offer, even with full support from the $\mathrm{MOH}$ in collaboration with key stakeholders in the public and private sectors. While pharmacists and assistant pharmacists were trained on injectable administration and could practice on dummy models, they could not provide injectables to interested cli- ents since pharmacists were not formally linked to a health center that could address potential complications.

Despite the reduced training length for private pharmacy staff in Senegal, absenteeism was common and private pharmacists' consistent participation in the training was hampered by their competing business demands. Legal restrictions may also have deterred their full participation in the training. Additional evidence is needed about how to tailor training formats and continued advocacy is needed to foster a more favorable legal environment for private pharmacies to provide a wider range of contraceptive methods. Despite these challenges, results of the study are being used by the Directorate of Maternal and Child Health and other key partners to advocate for the private sector to play a larger role in health service delivery through legal and policy changes.

\section{Ways forward}

The findings from all three countries demonstrate the potential for increased access to voluntary FP through task sharing and self-administration of injectables. Additionally, the studies demonstrate the benefit of using context-responsive IS to assess feasibility and acceptability of new service delivery options. Provision of a broad range of FP methods through drug shops, pharmacies, and self-administration offer important opportunities for women, including new users and young people. It is also essential to ensure that women receive high-quality care from both newly trained providers and existing providers offering new services. Ongoing commitment from national governments and collaboration among a variety of stakeholders will continue to support evidence-informed decisions to expand access and method choice.

\section{References}

1. World Bank Open Data. Accessed on 25 February 2020. https://data. worldbank.org/.

2. United Nations, Department of Economic and Social Affairs, Population Division. 2019. Estimates and Projections of Family Planning Indicators 2019. New York: United Nations.

3. Tsui, Amy O, Win Brown, and Qingfeng Li. 2017. "Contraceptive practice in sub-Saharan Africa," Population and Development Review, 43(S1): 166-191. doi: 10.1111/padr.12051

4. Keith, Bonnie et al. 2014. "Home-based administration of Sayana ${ }^{\circledR}$ Press: review and assessment of needs in low-resource settings," Contraception 89(5): 344-351. doi: 10.1016/j.contraception.2014.03.003

5. World Health Organization (WHO). 2017. "Task sharing to improve access to family planning/contraception," Summary Brief. Geneva: WHO. 
6. Kohn, Julia E. 2018. "DMPA self-administration can improve contraceptive access, continuation, and autonomy," The Lancet Global Health 6(5): PE481-E482. doi: 10.1016/S2214-109X(18)30077-9

7. World Health Organization. 2019. WHO Consolidated Guideline on Self-Care Interventions for Health: Sexual and Reproductive Health and Rights. Geneva: World Health Organization. https://www.who.int/reproductivehealth/ publications/self-care-interventions/en/

8. High-Impact Practices in Family Planning (HIP). 2013. "Drug shops and pharmacies: sources for family planning commodities and information." Washington, DC: USAID. Available from http://www.fphighimpactpractices.org/briefs/drugshops-and-pharmacies

9. High-Impact Practices in Family Planning (HIP). 2019. Task Sharing Family Planning Services to Increase Health Workeforce Efficiency and Expand Access: A Strategic Planning Guide. Washington, DC: USAID. Available from: https://www.fphighimpactpractices.org/guides/task-sharingfamily-planning-services/

10. Nai, Dela et al. 2019. "Introduction of DMPA-SC self-injection in Ghana: A feasibility and acceptability study using Sayana ${ }^{\circledR}$ Press," Research Report. Washington, DC: Population Council, The Evidence Project.

11. Ishaku, Salisu et al. 2018. "Examining and strengthening the role of patent and proprietary medicine vendors in the provision of injectable contraception in Nigeria," Research Report. Washington, DC: Population Council, The Evidence Project.

12. Chace Dwyer, Sara et al. 2018. "Feasibility of Patent and Proprietary Medicine Vendor provision of injectable contraceptives: preliminary results from implementation science research in Oyo and Nasarawa, Nigeria," Contraception 98(5): 460-462. doi: 10.1016/j. contraception.2018.08.015

13. Mbow, Fatou Bintou et al. 2019. "Les pharmacies privées dans l'offre de services de planification familiale au Sénégal : Une étude pilote," Dakar, Sénégal : Population Council, Le Projet Evidence.

14. Mbow, Fatou Bintou, Sara Chace Dwyer, and Nafissatou Diop. 2018. "Exploring of the potential for private pharmacies to provide family planning services in Senegal," Synthesis Brief. Dakar, Sénégal: Population Council, Evidence Project.

15. Mbow, Fatou Bintou et al. 2018. "Exploration du rôle potentiel des pharmacies privées dans l'offre de services de planification familiale au Sénégal," Analyse secondaire des données de ADEMAS. Dakar, Sénégal: Population Council, Le Projet Evidence.

16. The DHS Program. 2020. STATcompiler. Accessed on 1 July 2020. https://www.statcompiler.com/en/
17. Jain, Aparna et al. 2019. "Validation of two quality of care measures: results from a longitudinal study of reversible contraceptive users in India," Studies in Family Planning 50(2): 179-193. doi: 10.1111/sifp.1209

18. Chace Dwyer, Sara et al. 2019. "The effect of job aids on knowledge retention among Patent and Proprietary Medicine Vendors trained to administer injectable contraceptives: longitudinal results from implementation science in Nigeria," BMC Public Health 19: 1362. doi:10.1186/s12889-019-7668-2 https://bmcpublichealth biomedcentral.com/articles/10.1186/s12889-019-7668-2\#citeas

19. World Health Organization (WHO). 2015. Medical eligibility criteria wheel for contraceptive use. 5th edition. Geneva: WHO. https://www. who.int/reproductivehealth/publications/family_planning/mec-wheel5 th/en/

20. Program for Appropriate Technology for Health. 2014. "Sayana ${ }^{\circledR}$ Press clinical brief." www.path.org

21. Program for Appropriate Technology for Health. 2014. "Frequently asked questions about Sayana ${ }^{\circledR}$ Press.” www.path.org

22. FHI 360. 2015.Checklist for screening clients who want to initiate DMPA (or NET-EN). https://www.fhi360.org/sites/default/files/media/ documents/checklist-dmpa-english.pdf

23. FHI 360. 2008. A guide to effective and efficient provision of combined oral contraceptives (COCs). http://www.fhi.org

24. Population Council. 2015. The Balanced Counseling Strategy. A Toolkit for Family Planning Service Providers Working in High STI/HIV Prevalence Settings, 3rd edition. https://www.popcouncil.org/research/the-balancedcounseling-strategy-plus-a-toolkit-for-family-planning-service

25. IntraHealth. "La contraception Orale" PowerPointPresentation.

\section{Acknowledgements}

This brief summarizes key findings from several studies conducted by the Evidence Project/Population Council. We acknowledge the generous support of USAID, and we are grateful to the study participants who gave their time and shared their experiences. For additional information and resources, please visit https:/ / evidenceproject.popcouncil.org/.

\section{THE EVIDENCE PROJECT} Population Council 4301 Connecticut Ave. NW Washington, DC 20008 tel: +2022379400 evidenceproject@popcouncil.org
The Evidence Project is made possible by the generous support of the American people through the United States Agency for International Development (USAID) under the terms of cooperative agreement no. AID-OAA-A-13-00087. The contents of this document are the sole responsibility of the Evidence Project and Population Council and do not necessarily reflect the views of USAID or the United States Government.

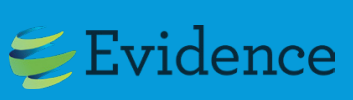

The Evidence Project uses implementation science-the strategic generation, translation, and use of evidence-to strengthen and scale up family planning and reproductive health programs to reduce unintended pregnancies worldwide. The Evidence Project is led by the Population Council.

Suggested Citation: The Evidence Project. 2020. “Expanding access and method choice: Evidence of client self-administration of injectables and private sector provision of family planning services in three West African countries," Learnings from the Evidence Project. Washington, DC: Population Council, The Evidence Project.

(๖) 2020 The Population Council, Inc.

Photo credits: Front cover-@PATH/Will Boase, Page 6- @ Caitlin Healy for CSIS (2016) 